\title{
Implementasi Data Mining Pada Klasifikasi Ketidakhadiran Pegawai Menggunakan Metode C4.5
}

\author{
Nandang Iriadi ${ }^{1}$, Lutfi Setioningtias ${ }^{2}$, Priatno $^{3}$ \\ ${ }^{1}$ Program Studi Teknologi Komputer, Fakultas Teknik dan Informatika, Universitas Bina Sarana Informatika, \\ J1. Kramat Raya No.98, Jakarta Pusat, DKI Jakarta 10450, Indonesia \\ ${ }^{2}$ Program Studi Sistem Informasi, Sekolah Tinggi Manajemen Informatika dan Komputer Nusa Mandiri \\ J1. Jatiwaringin No. 2, Cipinang Melayu, Makasar, Jakarta Timur - 13620, Indonesia \\ ${ }^{3}$ Program Studi Teknologi Informasi, Fakultas Teknik dan Informatika, Universitas Bina Sarana Informatika \\ J1. Kramat Raya No.98, Jakarta Pusat, DKI Jakarta 10450, Indonesia \\ e-mail : ${ }^{1}$ nandang.ndi@bsi.ac.id, ${ }^{2}$ lutfisetioningtias@ gmail.com, \\ ${ }^{3}$ priatno.prn@bsi.ac.id
}

Artikel Info : Diterima : 13-01-2021 | Direvisi : 17-01-2021 | Disetujui : 18-01-2021

\begin{abstract}
Abstrak - Tidak semua ketidakhadiran pegawai memiliki alasan yang selalu di cap buruk. Adapula ketidakhadiran yang bisa di toleransi oleh suatu instansi atau perusahaan, dimana alasan tersebut merupakan alasan yang dapat diterima misalnya dikarenakan alasan sakit, atau izin tertentu yang sekiranya dianggap masuk akal dan tentunya memiliki jangka waktu tertentu sehingga tidak begitu menyulitkan pihak tempatnya bekerja. Tujuan penelitian adalah mengetahui sejauh mana algoritma C4.5 dapat membantu perhitungan klasifikasi untuk menemukan solusi agar produktivitas kerja pegawai meningkat.Untuk menemukan solusi agar produktivitas kerja pegawai meningkat membutuhkan teknik dan cara tertentu yaitu dengan klasifikasi data mining menggunakan Algoritma C4.5. Supaya pengolahan data mendapatkan hasil yang baik, maka digunakan Tools Rapid Miner 5. Algoritma C4.5 termasuk jenis aturan klasifikasi pada Data Mining. Penting tidaknya suatu aturan klasifikasi dapat diketahui dengan dua parameter, yaitu Entropy dan Gain tertinggi. Setelah dilakukan pengujian, maka hasil yang didapat dari Algoritma C4.5 memiliki akurasi sebesar $81,08 \%$.
\end{abstract}

Kata Kunci : Ketidakhadiran, Algoritma C4.5, Data Mining, Rapid Miner 5

Abstract - Not all employee absences have reasons that are always labeled as bad. There is also an absence that can be tolerated by an agency or company, where these reasons are acceptable reasons, for example, due to illness, or certain permits that are considered reasonable and of course have a certain period so that it is not too difficult for the party where he works. The research objective is to determine the extent to which the C4.5 algorithm can help the classification calculation to find solutions so that employee works productivity increases. To find a solution so that employee work productivity increases requires certain techniques and methods, namely by classifying data mining using the C4.5 Algorithm. For data processing to get good results, Rapid Miner 5 Tools are used. The C4.5 algorithm is a type of classification rule in Data Mining. The importance of a classification rule can be determined by two parameters, namely Entropy and the highest Gain. After testing, the results obtained from the C4.5 Algorithm have an accuracy of $81.08 \%$.

Keywords: Absence, C4.5 Algorithm, Data Mining, Rapid Miner 5

\section{PENDAHULUAN}

Ketidakhadiran atau kealpaan individu terhadap pekerjaan atau tugas dan kajibannya yang sudah dimiliki oleh masing-masing individu tersebut dan berjalan secara rutin. Secara umum, absensi adalah bagian dari kinerja individual yang dikategorikan sebagai kemalasan dan termasuk dalam pelanggaran antara pegawai terhadap

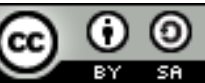

This work is licensed under a Creative Commons Attribution-ShareAlike 4.0 International License. 
atasannya dalam ruang lingkup formalitas pekerjaan di dalam suatu instansi atau perusahaan. Kebiasaan tidak hadir di tempat kerja merupakan suatu tindakan moral yang dipandang buruk di mata sosial masyarakat

Berdasarkan permasalahan di atas, penelitian ini mengambil data ketidakhadiran pegawai di tempat kerja selama 3 tahun dari salah satu perusahaan pengiriman di Brazil yang data-datanya di peroleh dari penyimpanan dataset University of California Irvine (UCI) Machine learning Repository. Tujuan penelitian adalah untuk mengetahui sejauh mana algoritma $\mathrm{C} 4.5$ dapat membantu perhitungan klasifikasi untuk menemukan solusi agar produktivitas kerja pegawai meningkat. Data-data yang tersimpan dan sudah tidak dipergunakan lagi dengan jumlah dataset yang cukup besar, yakni berjumlah 740 dataset ini membutuhkan sebuah teknik atau metode pengolahan data agar data tersebut bisa diolah sebagai suatu informasi yang dibutuhkan dan bermanfaat. Untuk mewujudkannya, maka metode yang digunakan dalam penelitian ini adalah metode Algoritma C4.5.

Pada prosesnya data mining akan mengekstrak informasi yang berharga dengan cara menganalisis adanya pola-pola ataupun hubungan keterkaitan tertentu dari data-data yang berukuran besar. Dengan adanya data mining dapat menemukan pengetahuan yang dapat dipergunakan oleh para praktisi kesehatan agar dapat meningkatkan kualitas pelayanan. Pengetahuan yang ditemukan dapat juga digunakan oleh praktisi medis untuk mengurangi jumlah efek samping dari obat untuk menyarankan lebih murah dalam terapi yang setara denngan berbagai alternatif. Proses mining data lebih dari sekedar analisa data yang meliputi pengklasifikasian, klastering, asosiasi dan prediksi. (M Anbarasi, E Anupriya, 2010)

Data Mining. Absensi adalah tingkat ketidakhadiran pegawai yang berkenaan dengan tanggung jawab. Saat ini banyak pegawai yang melanggar jam kerja, menaati jam kerja merupakan kewajiban seorang pegawai, yaitu masuk kerja dan menaati ketentuan jam kerja. (Ardyan Pratama, 2016)

"Sistem Pendukung Keputusan atau yang disebut dengan DSS (Decision Support System) adalah sistem berbasis komputer yang ditujukan untuk membantu pengambil keputusan dengan memanfaatkan data dan model untuk mengidentifikasi memecahkan masalah dan membuat keputusan”(Ichsan, Syahru, 2013)

Menurut (Christiana, 2013) mengemukakan bahwa: Organisasi telah dibentuk untuk memenuhi kebutuhan masyarakat. Dalam dunia yang kompetitif saat ini, organisasi harus berorientasi pada pertumbuhan. Hal ini memungkinkan ketika produktivitas dipastikan berkenaan dengan kuantitas dan kualitas produk. Ketidakhadiran dan pergantian karyawan memiliki dampak negatif terhadap produktivitas. Karyawan yang absen seringkali tidak dapat berkontribusi terhadap produktivitas dan pertumbuhan organisasi. Demikian pula, pergantian karyawan menyebabkan peningkatan biaya produksi.

Menurut (Hermawati, 2005), mengemukakan bahwa: Data mining adalah proses yang mempekerjakan satu atau lebih teknik pembelajaran komputer (machine lerning) untuk menganalisis dan mengekstraksi pengetahuan (knowledge) secara otomatis.

Knowledge Discovery In Databases ( KDD ) adalah proses non trivial untuk mencari dan mengidentifikasi pola (pattern) dalam data (Wahbeh, 2011)

Data mining menurut David Hand, Heikki Mannila, dan Padhraic Smyth dari MIT adalah analisa terhadap data (biasanya data yang berukuran besar) untuk menemukan hubungan yang jelas serta menyimpulkannya yang belum diketahui sebelumnya dengan cara terkini dipahami dan berguna bagi pemilik data tersebut. (Yuli Mardi, 2014)

Menurut (Widodo et al., 2013) mengemukakan bahwa: Pohon keputusan (decision tree) merupakan salah satu teknik terkenal dalam data mining dan merupakan salah satu metode yang populer dalam menentukan keputusan suatu kasus. Hal ini karena metode ini tidak memerlukan proses pengelolaan pengetahuan terlebih dahulu dan dapat menyelesaikan dengan sederhana kasus-kasus yang memiliki dimensi yang besar. Akurasinya sangat baik asalkan data yang akan dijadikan patokan merupakan data yang akurat.

Menurut Han dalam (Widodo et al., 2013) mengemukakan bahwa, “Algoritma C4.5 merupakan struktur pohon dimana terdapat simpul yang mende Penelitiankan atribut-atribut, setiap cabang menggambarkan hasil dari atribut yang diuji, dan setiap daun menggambarkan kelas. Algoritma C4.5 secara rekursif mengunjungi setiap simpul keputusan, memilih pembagian yang optimal, sampai tidak bisa dibagi lagi. Algoritma C4.5 menggunakan konsep information gain atau entropy reduction untuk memilih pembagian yang optimal". 
Menurut Kusrini dalam (Widodo et al., 2013) Terdapat beberapa tahap dalam membuat sebuah pohon keputusan dengan algoritma $\mathrm{C} 4.5$, yaitu:

1. Menyiapkan data training. Data training biasanya diambil dari data histori yang pernah terjadi sebelumnya dan sudah di kelompokkan ke dalam kelas-kelas tertentu.

2. Menentukan akar dari pohon. Akar akan diambil dari atribut yang terpilih, dengan cara menghitung nilai gain dari masing-masing atribut, nilai gain yang paling tinggi yang akan menjadi akar pertama. Sebelum menghitung nilai gain dari atribut, hitung dahulu nilai entropy. Untuk menghitung nilai entropy digunakan rumus:

$$
\operatorname{Entropy}(S)=\sum_{i=1}^{n}-\text { pi. } \log _{2} p i
$$

Keterangan:

$\mathrm{S} \quad=$ himpunan kasus

$\mathrm{n} \quad=$ jumlah partisi $\mathrm{S}$

pi $\quad$ proporsi Si terhadap $\mathrm{S}$

3. Kemudian hitung nilai gain menggunakan rumus:

$\operatorname{Gain}(S, A)=$ Entropy $(S)-\sum_{i=1}^{n} \frac{|S i|}{|S|}$

* Entropy (Si)

Keterangan:

$\mathrm{S} \quad=$ himpunan kasus

A = fitur

$\mathrm{n} \quad=$ jumlah partisi atribut $\mathrm{A}$

$|\mathrm{Si}|=$ proporsi $\mathrm{S} i$ terhadap $\mathrm{S}$

$|\mathrm{S}|$ = jumlah kasus dalam $\mathrm{S}$

4. Ulangi langkah ke-2 hingga semua record terpartisi.

5. Proses partisi pohon keputusan akan berhenti saat:

a. Semua record dalam simpul $\mathrm{N}$ mendapat kelas yang sama.

b. Tidak ada atribut di dalam record yang dipartisi lagi.

c. Tidak ada record di dalam cabang yang kosong.

Menurut (Nofriansyah, 2014) mengemukakan bahwa, Adapun kriteria atau ciri-ciri dari sebuah keputusan adalah sebagai berikut:

1. Banyak pilihan atau alternatif.

2. Ada kendala atau surat.

3. Mengikuti suatu pola atau model tingkah laku, baik yang terstruktur maupun tidak terstruktur.

4. Banyak input atau variabel.

5. Ada faktor resiko, dibutuhkan kecepatan, ketepatan, dan keakuratan.

Menurut (Mutoi Siregar \& Puspabhuana, 2018), RapidMiner merupakan perangkat lunak yang bersifat terbuka (open source). RapidMiner adalah sebuah solusi untuk melakukan analisis terhadap data mining, text mining dan analisis prediksi. RapidMiner menggunakan berbagai teknik deskriptif dan prediksi dalam memberikan wawasan kepada pengguna sehingga dapat membuat keputusan yang paling baik. RapidMiner memiliki kurang lebih 500 operator data mining, termasuk operator untuk input, output, data preprocessing dan visualisasi. RapidMiner merupakan software yang berdiri sendiri untuk analisis data dan sebagai mesin data mining yang dapat diintegrasikan pada produknya sendiri. RapidMiner ditulis dengan munggunakan bahasa java sehingga dapat bekerja di semua sistem operasi.

Menurut (Sugiyono, 2010)mengemukakan bahwa: Nonprobability Sampling adalah teknik pengambilan sampel yang tidak memberi peluang atau kesempatan sama bagi setiap unsur atau anggota populasi untuk dipilih menjadi sampel. Teknik sampel ini meliputi sampling sistematis, kuota, insidental, purposive, jenuh, dan snowball.

Sedangkan teknik pengambilan sampel dari Nonprobablity sampling yang diambil di dalam penelitian ini adalah Sampling Sistematis. 
Menurut (Sugiyono, 2010)mengemukakan bahwa, "Sampling sistematis adalah teknik pengambilan sampel berdasarkan urutan dari anggota populasi yang telah diberi nomor urut".

Misalnya anggota populasi yang terdiri dari 100 orang. Dari semua anggota tersebut diberi nomor urut, yaitu nomor urut 1 sampai dengan nomor urut 100. Pengambilan sampel dapat dilakukan dengan nomor ganjil saja, genap saja atau dengan kelipatan dari bilangan tertentu, misalnya kelipatan dari bilangan 5. Untuk itu maka yang diambil sebagai sampel adalah nomor urut 1,5,10,15,20, dan seterusnya sampai dengan 100 .

\section{METODE PENELITIAN}

Dalam penyusunan Penelitian ini, diperlukan beberapa tahapan untuk mencapai bagian yang telah ditetapkan sebelumnya. Tahapan penelitan yang dilakukan sebagai berikut:
a. Fase Pemahaman Bisnis (Business Understanding Phase).
b. Fase Pemahaman Data (Data Understanding Phase).
c. Fase Pengolahan Data (Data Preparation phase).
d. Fase Pemodelan (Modelling Phase).
e. Fase Evaluasi (Evaluation Phase).
f. Fase Penyebaran (Deployment Phase)

Terdapat 20 Atribut untuk kebutuhan penelitian, diantaranya adalah, Alasan Ketidakhadiran, Bulan Ketidakhadiran, Hari Dalam Seminggu, Musim, Biaya Transportasi, Jarak Tempuh/km, Waktu Pelayanan, Umur, Rata-rata Bekerja/Hari, Target yang Dicapai, Kegagalan Disiplin, Pendidikan, Anak, Peminum, Perokok, Binatang Peliharaan, Berat Badan, Tinggi Badan, Indeks Masa Tubuh, dan Waktu Ketidakhadiran dalam Jam.

Dalam penelitian ini, media pengumpulan datanya adalah berupa data sekunder. Data sekunder yang digunakan di dalam penelitian ini adalah menggunakan data dari University of California Irvine (UCI) Machine learning Repositor. Data yang diambil adalah data ketidakhadiran pegawai di tempat kerja selama 3 tahun dari salah satu perusahaan pengiriman di Brazil.

Populasi dalam penelitian ini merupakan semua data karyawan pengiriman sebanyak 740 record data dari salah satu data perusahaan di Brazil selama 3 tahun yang data-datanya tersimpan di University of California Irvine (UCI) Machine learning Repository.

Sampel yang digunakan di dalam penelitian ini adalah sebanyak 370 record data dan teknik pengambilan sampelnya adalah menggunakan salah satu teknik pengambilan sampel dari Nonprobability Sampling, yaitu Sampling Sistematis. Dikarenakan di dalam teknik pengambilan sampel secara sampling sistematis adalah menggunakan nomor urut sebagai acuannya, maka peneliti menggunakan urutan nomor urut ganjil yang dimulai dari nomor urut 1 sampai dengan nomor urut 739 yang pengambilan nomor urutnya tidak boleh lebih dari banyaknya populasi yang diambil, yaitu 740 record data.

1. Perhitungan Manual Algoritma C4.5.

Pada proses perhitungan manual, tahap-tahap untuk menentukan pohon keputusan (Decision Tree) dengan mengunakan algoritma $\mathrm{C} 4.5$ adalah sebagai berikut:

a. Mengumpulkan dan menyiapkan dataset.

b. Menghitung Nilai Entropy.

c. Menghitung Nilai Gain pada setiap atribut untuk mencari nilai gain yang tertinggi dan dijadikan sebagai Node Akar.

d. Proses perhitungan nilai-nilai pada node akar dan cabang.

2. Implementasi Pohon Keputusan (Decision Tree) dengan Rapid Miner.

Pada tahap ini dilakukan proses perhitungan menggunakan aplikasi Rapid Miner yang bertujuan untuk membandingkan hasil perhitungan manual dengan hasil perhitungan aplikasi. Pengujian dilakukan agar mendapatkan tingkat keakuratan data dan dapat ditarik kesimpulannya dari hasil tersebut.

\section{HASIL DAN PEMBAHASAN}

Penelitian ini bertujuan untuk mengetahui sejauh mana algoritma C4.5 dapat membantu perhitungan klasifikasi untuk menemukan solusi agar produktivitas kerja pegawai meningkat. Di dalam menentukan hasil 
penelitian ini, peneliti menggunakan dataset sebanyak 740 record data dengan sampel penelitian yang diambil adalah sebanyak 370 record data.

\section{Perhitungan Manual Algoritma C4.5.}

Langkah untuk menentukan pohon keputusan dengan menggunakan algoritma C4.5 dengan memakai sampel dataset sebanyak 370, yaitu:

1. Menyiapkan sampel dataset sebanyak 370 data untuk digunakan dalam penelitian ini. Dataset biasanya diambil dari data primer yang sebelumnya sudah dikelompokkan ke dalam kelas-kelas tertentu.

2. Hitung nilai entropy.

Setelah dilakukan perhitungan entropy seperti rumus, di dapat hasil nilai entropy sebagai berikut:

Total Entropy

$$
\begin{aligned}
& =\left(\left(\frac{-348}{370}\right) \times \log _{2}\left(\frac{348}{370}\right)\right)+\left(\left(\frac{-22}{370}\right) \times \log _{2}\left(\frac{22}{370}\right)\right) \\
& =0,0832+0,2421 \\
& =0,3253
\end{aligned}
$$

3. Setelah itu hitunglah nilai gain untuk setiap atribut, lalu pilih nilai gain yang tertinggi untuk dijadikan akar dari pohon. Hitunglah nilai gain menggunakan rumus. Misalkan untuk aribut 'Bulan Ketidakhadiran', didapatkan nilai gain sebagai berikut:

$\operatorname{Gain}(S, A)=\operatorname{Entropy}(S)-\sum_{i=1}^{n} \frac{|S i|}{|S|} * \operatorname{Entropy}(S i)$

Gain (Bulan Ketidakhadiran)

$$
\begin{aligned}
=0,3253-\left(\left(\left(\frac{23}{370}\right) \times 0\right)+\left(\left(\frac{34}{270}\right) \times 0\right)+\left(\left(\frac{45}{370}\right) \times 0,2623\right)+\left(\left(\frac{24}{370}\right) x 0\right)\right. \\
+\left(\left(\frac{31}{370}\right) \times 0,4587\right)+\left(\left(\frac{27}{370}\right) \times 0,2285\right)+\left(\left(\frac{37}{370}\right) \times 0,3034\right) \\
+\left(\left(\frac{27}{370}\right) x 0\right)+\left(\left(\frac{27}{370}\right) \times 0,6913\right)+\left(\left(\frac{34}{370}\right) \times 0,6024\right) \\
\left.+\left(\left(\frac{36}{370}\right) x 0,5033\right)+\left(\left(\frac{25}{370}\right) \times 0\right)\right)
\end{aligned}
$$

$=0,3253-$

$(0+0+0,0319+0+0,0384+0,0167+0,0303+0+$

$0,0504+0,0554+0,0490)=0,3253-0,2721$

$=0,0532$

a. Proses untuk node akar.

Macam-macam atributnya adalah alasan ketidakhadiran, bulan ketidakhadiran, hari dalam seminggu, musim, biaya transportasi, jarak tempuh/km, waktu pelayanan, umur, rata-rata bekerja/hari, target yang dicapai, kegagalan disiplin, pendidikan, anak, peminum, perokok, binatang peliharaan, berat badan, tinggi badan, indeks masa tubuh, dan waktu ketidakhadiran dalam jam. Setiap atribut memiliki nilai. Sedangkan label kelasnya ada pada kolom keputusan yaitu Tidak dan Ya. Kolom keputusan didapatkan dari nilai atribut "Kegagalan Disiplin" yang dijadikan sebagai label kelas untuk kemudian nilai "Tidak" dan "Ya" dijadikan sebagai kolom keputusan. Nilai "Tidak" berarti "Kegagalan disiplin = Tidak" dan nilai "Ya" berarti "Kegagalan disiplin = Ya". Kemudian data dianalisis, dataset tersebut memiliki 370 kasus yang terdiri dari 348 karyawan mengalami Kegagalan disiplin $=$ Tidak dan 22 kasus karyawan mengalami Kegagalan disiplin = Ya .

Tabel 1. Hasil gain tertinggi untuk Node Akar

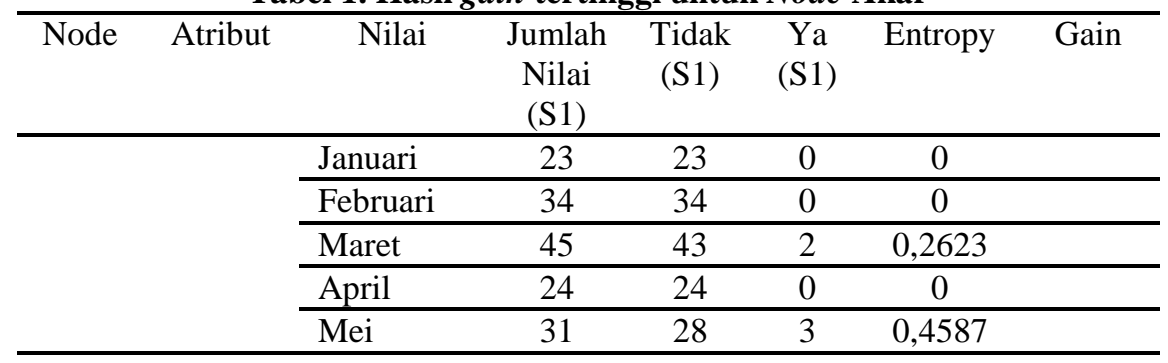




\begin{tabular}{llllllll}
\hline \multirow{3}{*}{1} & Juni & 27 & 26 & 2 & 0,2285 & \\
\cline { 3 - 7 } $\begin{array}{l}\text { Bulan } \\
\text { Ketidak } \\
\text { hadiran }\end{array}$ & Juli & 37 & 35 & 2 & 0,3034 & \\
\cline { 2 - 7 } & Agustus & 27 & 27 & 0 & 0 & \\
\cline { 2 - 7 } & September & 27 & 22 & 5 & 0,6913 & \\
\cline { 2 - 7 } & Oktober & 34 & 29 & 5 & 0,6024 & \\
\cline { 2 - 7 } & November & 36 & 32 & 4 & 0,5033 & \\
\hline & Desember & 25 & 25 & 0 & 0 & \\
\hline & Total & 370 & 348 & 22 & 3,0499 & 0,0532 \\
\hline
\end{tabular}

Dari hasil tabel 1 setelah dihitung nilai gain dari setiap atribut. Maka hasilnya adalah atribut 'Bulan Ketidakhadiran' yang mendapat nilai gain tertinggi dengan hasil 0,0532. Bentuk decision tree atau pohon keputusannya akan menjadi seperti berikut ini:

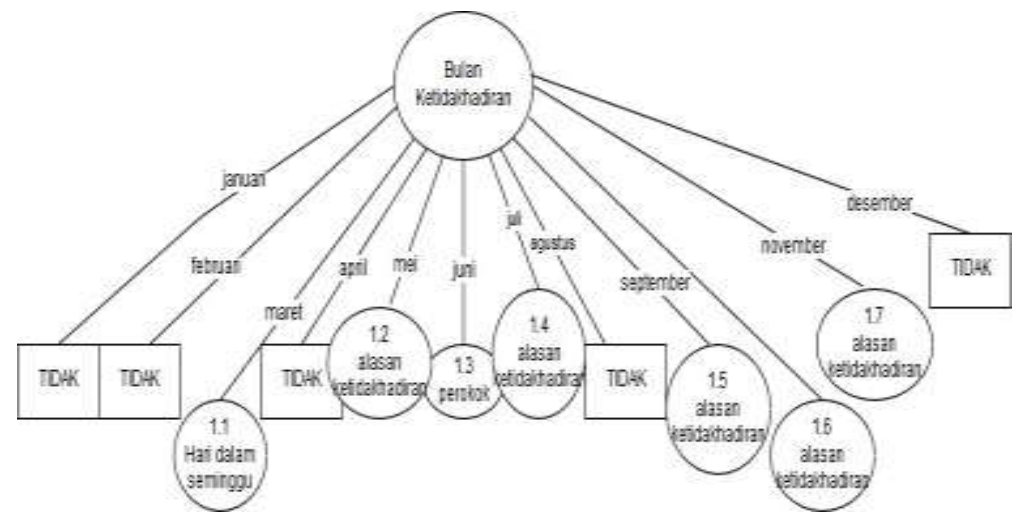

Gambar 1. Pohon Keputusan Node Akar

Setelah dihitung nilai gain dari setiap atribut. Maka hasil akhirnya adalah atribut 'Indeks Masa Tubuh' dengan nilai '19-25' yang mendapat nilai gain tertinggi dengan hasil 0,4834 dan ditandai oleh kolom berlatar belakang warna merah pada tabel. Bentuk decision tree atau pohon keputusannya akan menjadi seperti berikut ini:

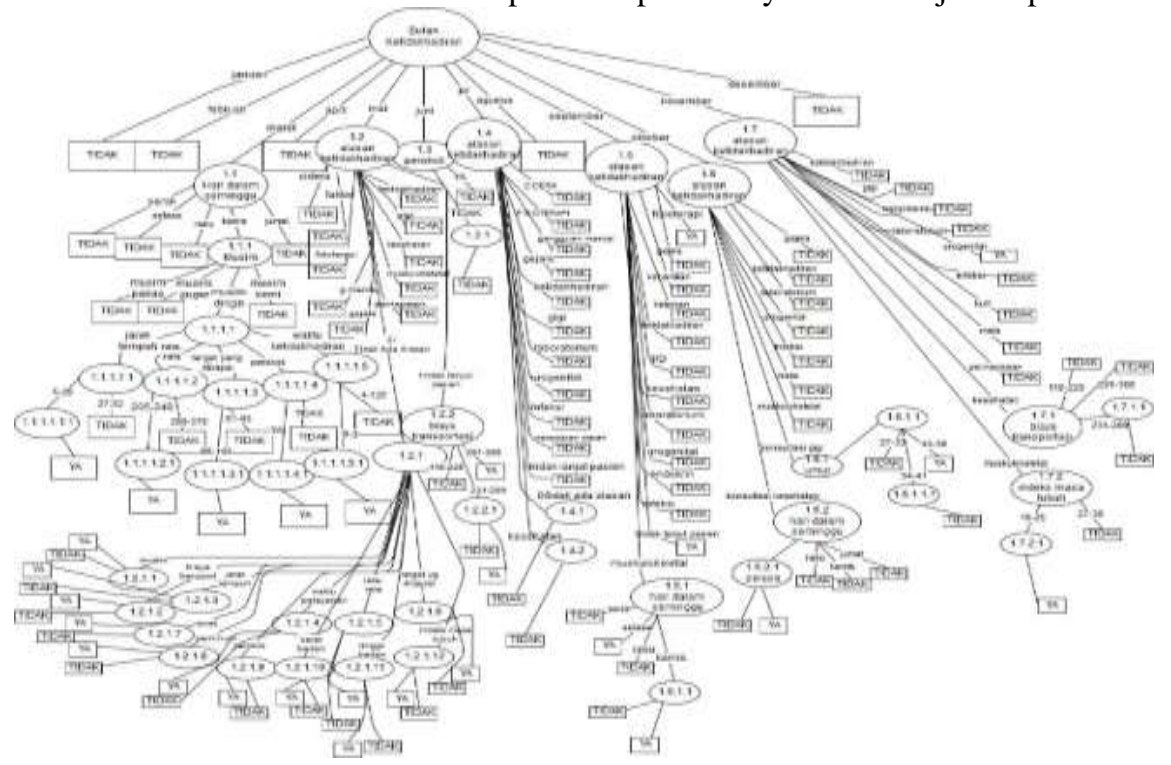

Gambar 2. Pohon Keputusan Node 1.7.2.1

Bentuk aturan IF THEN untuk pohon keputusan dengan algoritma $\mathrm{C} 4.5$ adalah sebagai berikut:

1. IF Bulan Ketidakhadiran dengan nilai = Januari THEN Keputusan = Tidak.

2. $I F$ Bulan Ketidakhadiran dengan nilai $=$ Februari $T H E N$ Keputusan $=$ Tidak.

3. $I F$ Bulan Ketidakhadiran dengan nilai $=$ April $T H E N$ Keputusan $=$ Tidak.

4. $I F$ Bulan Ketidakhadiran dengan nilai $=$ Agustus $T H E N$ Keputusan $=$ Tidak .

5. $I F$ Bulan Ketidakhadiran dengan nilai $=$ Desember $T H E N$ Keputusan $=$ Tidak.

6. IF Bulan Ketidakhadiran dengan nilai $=$ November $A N D$ Alasan Ketidakhadiran $=$ konsultasi kesehatan $A N D$ Biaya Transportasi $=291-388$ THEN Keputusan $=$ Tidak 
7. $I F$ Bulan Ketidakhadiran dengan nilai $=$ November $A N D$ Alasan Ketidakhadiran $=$ konsultasi kesehatan $A N D$ Biaya Transportasi $=231-289$ THEN Keputusan $=$ Tidak .

8. IF Bulan Ketidakhadiran dengan nilai = November $A N D$ Alasan Ketidakhadiran = penyakit pada sistem muskuloskeletal dan jaringan ikat AND Indeks Masa Tubuh = 27-38 THEN Keputusan = Tidak.

9. IF Bulan Ketidakhadiran dengan nilai $=$ November $A N D$ Alasan Ketidakhadiran $=$ penyakit pada sistem muskuloskeletal dan jaringan ikat AND Indeks Masa Tubuh = 19-25 THEN Keputusan = Ya.

10. IF Bulan Ketidakhadiran dengan nilai = November $A N D$ Alasan Ketidakhadiran = penyakit pada sistem muskuloskeletal dan jaringan ikat AND Indeks Masa Tubuh =19-25 THEN Keputusan = Ya.

\section{Implementasi Pohon Keputusan (Decision Tree) dengan Rapid Miner.}

Berikut ini adalah hasil pohon keputusan atau decision tree menggunakan aplikasi rapid miner.

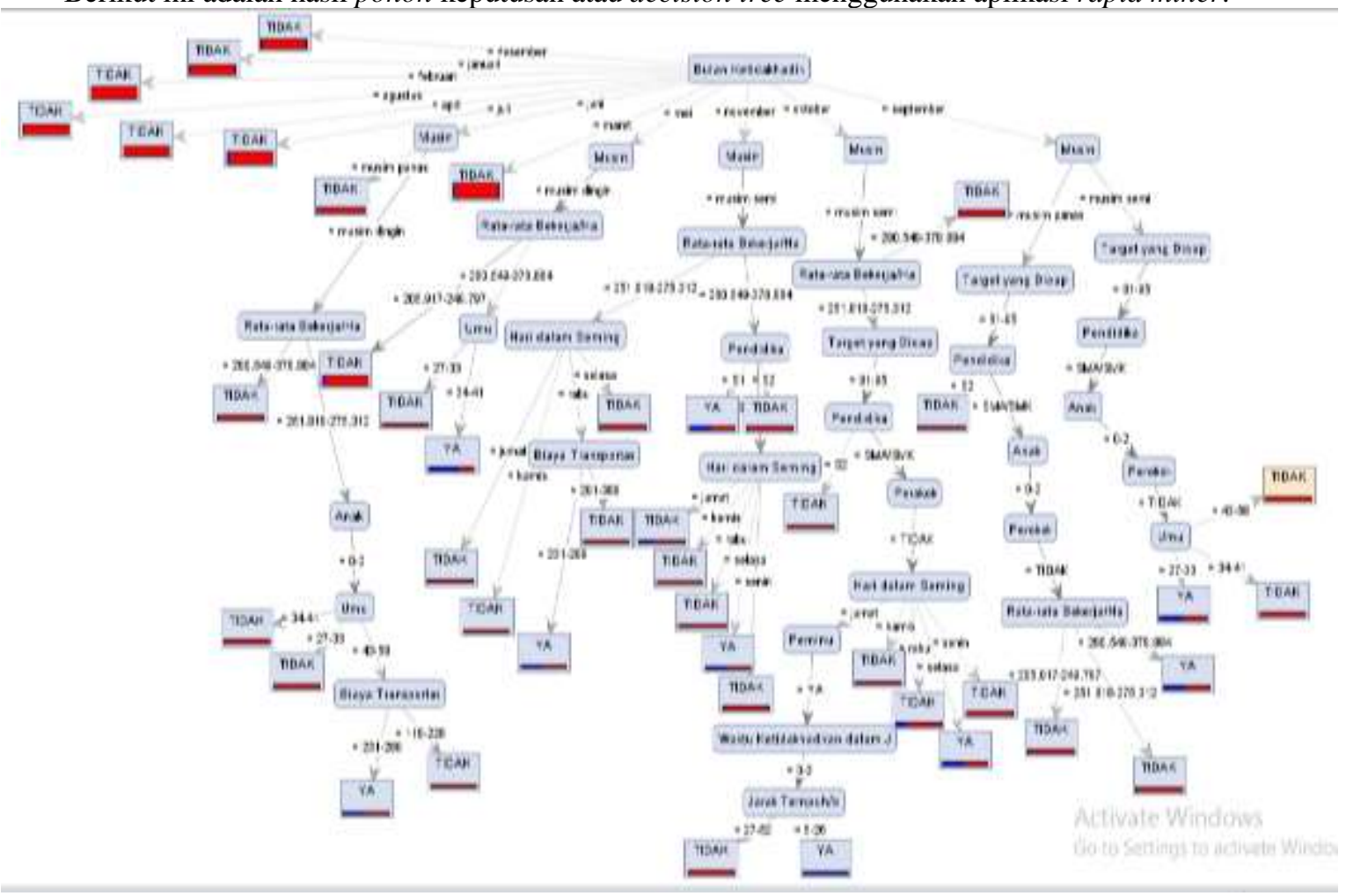

Gambar 3. Desain Model C4.5

Berdasarkan rule classification diatas, untuk mempermudah pemahaman data, maka dibentuk aturan $I F$ THEN yaitu sebagai berikut:

1. IF Bulan Ketidakhadiran = September AND Musim = Musim Panas AND Target yang Dicapai $=81-95$ AND Pendidikan $=$ S2 THEN Keputusan $=$ Tidak ELSE Pendidikan $=$ SMA/SMK AND Anak = 0-2 AND Perokok = TIDAK AND Rata-rata Bekerja/Hari = 205.917-249.797 THEN Keputusan = Tidak ELSE Rata-rata Bekerja/Hari = 251.818-275.312 THEN Keputusan = Tidak ELSE Rata-rata Bekerja/Hari = 280.549-378.884 THEN Keputusan $=$ Ya.

2. IF Bulan Ketidakhadiran = September AND Musim = Musim Semi AND Target yang Dicapai $=81-95$ AND Pendidikan $=$ SMA $/$ SMK AND Anak $=0-2$ AND Perokok $=$ TIDAK AND Umur $=27-33$ THEN Keputusan $=$ Ya ELSE Umur = 34-41 THEN Keputusan $=$ Tidak ELSE Umur $=43-58$ THEN Keputusan $=$ Tidak.

Tabel 2. Hasil Confusion Matrix.

Accuracy : $81.08 \%$ 


\begin{tabular}{lccc}
\hline & $\begin{array}{c}\text { True } \\
\text { Ya }\end{array}$ & $\begin{array}{c}\text { True } \\
\text { Tidak }\end{array}$ & $\begin{array}{c}\text { Class } \\
\text { Precision }\end{array}$ \\
\hline Pred. Ya & 2 & 19 & $9.52 \%$ \\
\hline Pred. Tidak & 2 & 88 & $97.78 \%$ \\
\hline Class Recall & $50.00 \%$ & $82.24 \%$ & \\
\hline
\end{tabular}

Dari hasil evaluasi pada tabel 2. menunjukkan bahwa tingkat akurasi yang dihasilkan adalah sebesar 81,08\% atau sebesar 0,8108\% yang berarti masuk pada klasifikasi sangat baik untuk hasil klasifikasi pegawai yang mengalami Kegagalan Disiplin = Ya dan Kegagalan Disiplin = Tidak . Berdasarkan hasilnya, dapat dikatakan bahwa pegawai yang mendapatkan Kegagalan Disiplin = Tidak adalah yang terbanyak dibandingkan dengan pegawai yang mendapatkan Kegagalan Disiplin = Ya sehingga akan berdampak baik untuk produktivitas kerja pegawai dan sangat menguntungkan bagi perusahaan tempatnya bekerja.

\section{KESIMPULAN}

Berdasarkan hasil penelitian serta pembahasan, maka dapat ditarik beberapa kesimpulan antara lain sebagai berikut:

1. Pemilihan atribut Alasan Ketidakhadiran, Bulan Ketidakhadiran, Hari Dalam Seminggu, Musim, Biaya Transportasi, Jarak Tempuh/Km, Waktu Pelayanan, Umur, Rata-Rata Bekerja/Hari, Target Yang Dicapai, Kegagalan Disiplin, Pendidikan, Anak, Peminum, Perokok, Binatang Peliharaan, Berat Badan, Tinggi Badan, Indeks Masa Tubuh, Dan Waktu Ketidakhadiran Dalam Jam dapat menjadi kriteria penilaian terhadap klasifikasi kegagalan disiplin pegawai yang bernilai "Ya" dan "Tidak".

2. Penelitian dengan data Ketidakhadiran Pegawai di Tempat Kerja telah dilakukan penelitian menggunakan metode Neuro Fuzzy Network yang mana penelitian sebelumnya tersebut menggunakan data yang sama. Penelitian ini berpatokan pada penelitian sebelumnya, namun menggunakan metode yang berbeda, yaitu menggunakan metode Algoritma C4.5.

3. Berdasarkan hasil perhitungan manual dan rapid miner ternyata menghasilkan pohon keputusan yang berbeda pada hasil cabang dan daun, namun menghasilkan hasil yang sama pada Node akar dan cabang pertama.

4. Sistem yang digunakan dengan rapid miner dapat membantu dalam menentukan kriteria data pegawai yang bersifat "Ya, gagal disiplin" atau "Tidak, gagal disiplin". Sehingga dapat membantu pihak perusahaan dalam pengambilan keputusan terhadap peraturan absensi pegawai.

5. Algoritma C4.5 dapat menghasilkan rule atau aturan untuk menggambarkan proses yang terkait dengan kegagalan disiplin.

6. Dari hasil yang diujikan menggunakan confusion matrix, di dapatkan hasil bahwa Algoritma decision tree C4.5 mengklasifikasikan data dengan tingkat akurasi $81,08 \%$ dalam memprediksi jumlah pegawai yang mengalami kegagalan disiplin atau tidak. Nilai class precision dan class recall di dapatkan hasil masing-masing adalah 9,52\% dan 97,78\% untuk nilai class precision dan 50,00\% dan 82,24\% untuk nilai class recall. Berdasarkan hasil tersebut, dapat diartikan bahwa hasil dari tingkat akurasi sebesar 81,08\% mendapatkan hasil yang sangat baik untuk mengklasifikasi Ketidakhadiran pegawai dalam mendapatkan prediksi kegagalan disiplin pegawai.

\section{REFERENSI}

Ardyan Pratama, H. L. (2016). Implementasi Data Mining Menggunakan Metode Deskripsi Untuk Menemukan Pola Absensi Di Badan Kepegawaian Daerah Kota Semarang. Data Mining, 15(3), 207-216.

Christiana, M. B. (2013). Organizational Behaviour. In Organizational Behaviour. Educreation Publishing. https://doi.org/10.4324/9780203857595

Hermawati, F. A. (2005). Data Mining Data mining. In Mining of Massive Datasets (Vol. 2, Issue January 2013). Andi Offset. https://www.cambridge.org/core/product/identifier/CBO9781139058452A007/type/book_part

Ichsan, Syahru, T. . (2013). Sistem Pendukung Keputusan Pemilihan Penerima Beasiswa Mahasiswa Kurang Mampu Pada Stmik Budidarma Medan Menerapkan Metode Profile Matching. Pelita Informatika Budi Darma, 5(1), 2.

M Anbarasi, E Anupriya, N. C. S. N. I. (2010). Enhanced Prediction of Heart Disease with Feature Subset Selection using Genetic Algorithm Enhanced Prediction of Heart Disease with Feature Subset Selection using Genetic Algorithm. International Journal of Engineering Science and Technology, 2(10), 5370-5376.

Mutoi Siregar, A., \& Puspabhuana, A. (2018). Data Mining: Pengelolaan Data Menjadi Informasi dengan 
RapidMiner (1st $\quad$ ed.). $\quad$ CV. $\quad$ Kekata $\quad$ Group. https://books.google.co.id/books?id=rTlmDwAAQBAJ\&printsec=frontcover $\& \mathrm{hl}=\mathrm{id} \# \mathrm{v}=$ onepage $\& \mathrm{q} \& \mathrm{f}=\mathrm{fal}$ se

Nofriansyah, D. (2014). Konsep Data Mining Vs Sistem Pendukung Keputusan (1st ed.). DEEPUBLISH.

Wahbeh, dkk. (2011). A Comparison Study between Data Mining Tools over some Classification Methods. International Journal of Advanced Computer Science and Applications, 1(3). https://doi.org/10.14569/specialissue.2011.010304

Widodo, P. P., Handayanto, R. T., \& Herlawati. (2013). Penerapan Data Mining dengan Matlab. In Rekayasa Sains. Rekayasa Sains. www.biobses.com

Yuli Mardi. (2014). Analisa Data Rekam Medis Untuk Menentukan Penyakit Terbanyak Berdasarkan International Clasification Of Disease (ICD) menggunakan Decesion Tree C.45 (Studi Kasus RSU. CBMC Padang. UPI YPTK Padang, 213-219. 